\title{
Grinding Fly Ash Process and Equipment with Vertical Milling Machine
}

\author{
RUI FANG LI DONG YA SONG \\ Zhengzhou University of Industrial Technology,Zhengzhou 451150
}

\begin{abstract}
Keywords: vertical milling machine; grinding system; fly ash
Abstract: A new ash grinding process was proposed,with the application of vertical grinding mill systems to grinding,sorting, and collection process. The process by designing a new type of vertical grinding system to solve the small particles of fly ash in the state is not easy grinding problem,significantly reducing the grinding costs,footprint,investment costs,improving grinding efficiency and degree of automation. The technology and equipment have been put into use in Shougang Jingtang Iron and Steel Co.,Ltd.
\end{abstract}

\section{Introduction}

Fly ash from coal combustion flue gas after the closing down of fine ash capture.In China,Coal-fired thermal power plant total annual emissions of fly ash increases every year,In 2010 about 300 million tons, which not only pollutes the environment, but also takes up a lot of land.Therefore, it is imperative to fly governance.Since fly ash can be used for pouring concrete, high strength cement and new building materials [1], and so on.So,there has practical significance and far-reaching historical significance to achieve coordinated development of economy and society through its utilization[2].Shougang Group to respond to the call of the national energy saving, made of industrial solid waste fly ash recycling project,to handle 300,000 tons of solid waste generated by the power plant fly ash every year which make turning waste into treasure. The author studied the vertical milling machine grinding ash process, which improves the grinding efficiency, to meet the requirements of the project.

\section{fly ash handling equipment}

Ash grinding in the country started relatively late [3], which is still relatively superficial.Currently,coal ash tube mill grinding equipment is used by the transition from the cement tube mill, therefore, whether the mill structure or the technical parameters, and cement mill comparisons are not changed, the lack of relevance.Fly tube mill apply the cement tube mill tube mill technology,in theory it is unscientific, practically impossible to achieve the desired efficiency.Currently ash tube mill has a common problem:the mill material flow too fast,Pellet ratio lower, serious "over-grinding"、 the technical parameters is unreasonable and grinding grading, linings, diaphragm plate, export grate plate structure is lack of specific.Meanwhile, the tube mill also has a large area, low energy use, low productivity, high one-time investment, particulate unevenness prominent and serious shortcomings. Vertical milling machine is a more rapid developgrinding equipment in recent years, which has high grinding efficiency, low power consumption, high drying capacity, allowing large size material into the mill, the grinding process is simple, small footprint, low construction costs, low tone, low wear, long life, easy to operate, etc [5].Currently, vertical milling machine equipment is used on the market are HRM series, MLS series (6).Combination of all the results of the literature and laboratory experiments of view,due to the small fineness of fly ash (coal ash more than half of the raw material can reach the national standard two ash), the current structure of the vertical milling machine grinding of fly ash exists in difficulty [7]. 


\section{vertical mill grinding process}

Fly grinding process block diagram shown in Figure 1.Analog field effect Figure 2 for the process systems. Figure 3 is a vertical milling machine model diagram. The new process uses a vertical milling machine (including the mill body and the upper separator at the bottom, two big whirlwind processor, fans, small whirlwind processor, piping and other components of the closed system, efficiency of about 75\%), after baghouse again collected (about $99.99 \%$ efficiency, particle concentration contained in the gas so far has been to meet environmental emission standards), clean gas is then connected to the import of complete mill closed cycle through the fan and piping.A small cyclone system is connected to the pipe between the fans and the mill, whose special significance is to ensure the mill internal pressure pressure is negative, in order to achieve the mill seal is not particularly good there is no particles through the void drifting out environmental pollution [8].

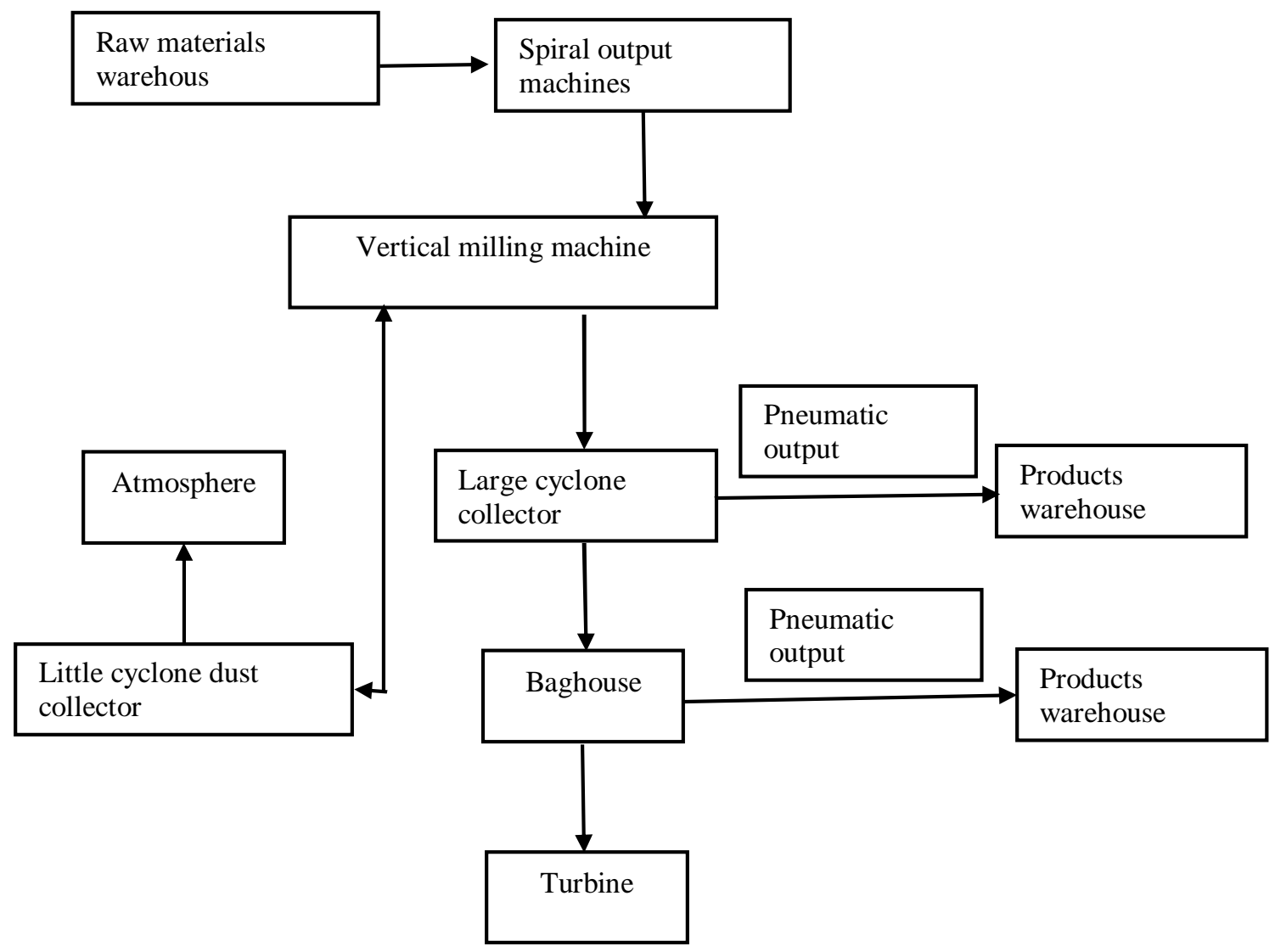

Fig. 1 Vertical milling machine grinding

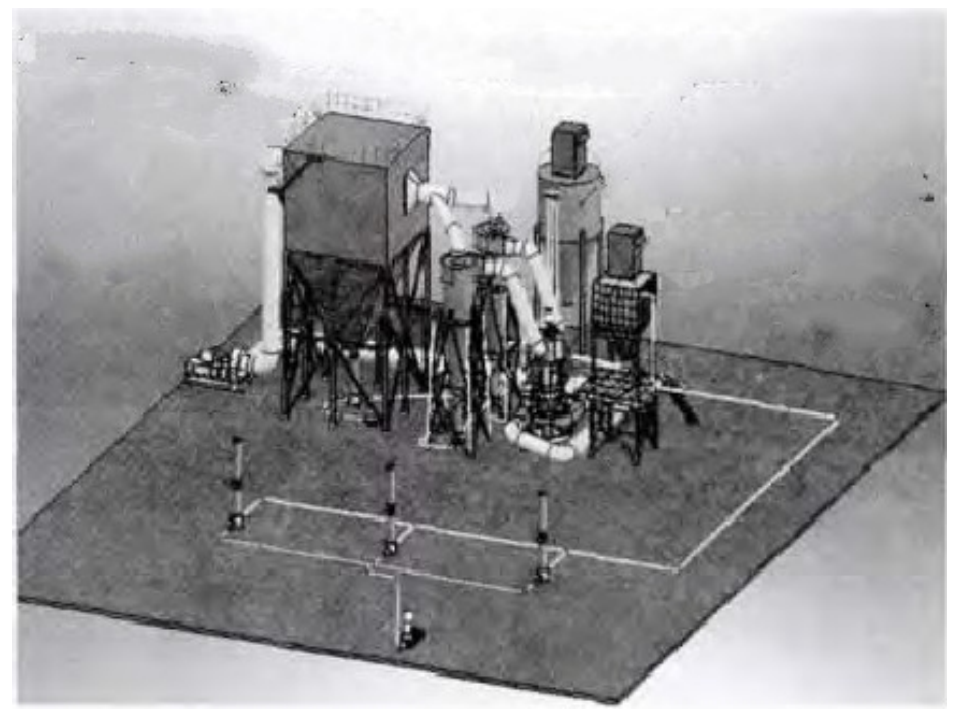

Fig. 2 Simulation scene renderings 


\section{key process equipment}

new vertical milling machine

The difference between the new vertical milling machine with conventional vertical mill is:using six evenly distributed tire roller,which can increases in the effective contact area and reduce the probability of large particles with air rising, extending the effective grinding time, reduce energy consumption, improve production efficiency .At the same time, the new mill roll material and quick change mechanism is applied to increase the wear resistance and reduce the replacement of grinding roll skin, improve the mill service life and maintenance time, improve the production capacity and can reduce the maintenance time and cost.New type powder selecting machine, takes appropriate dynamic blade number, width, leaf angle, select powder machine classification efficiency and classification accuracy are improved, and the inverter motor control is used,which substantially increased the separator cage speed range for particle production to meet the requirements to provide an effective guarantee[9].

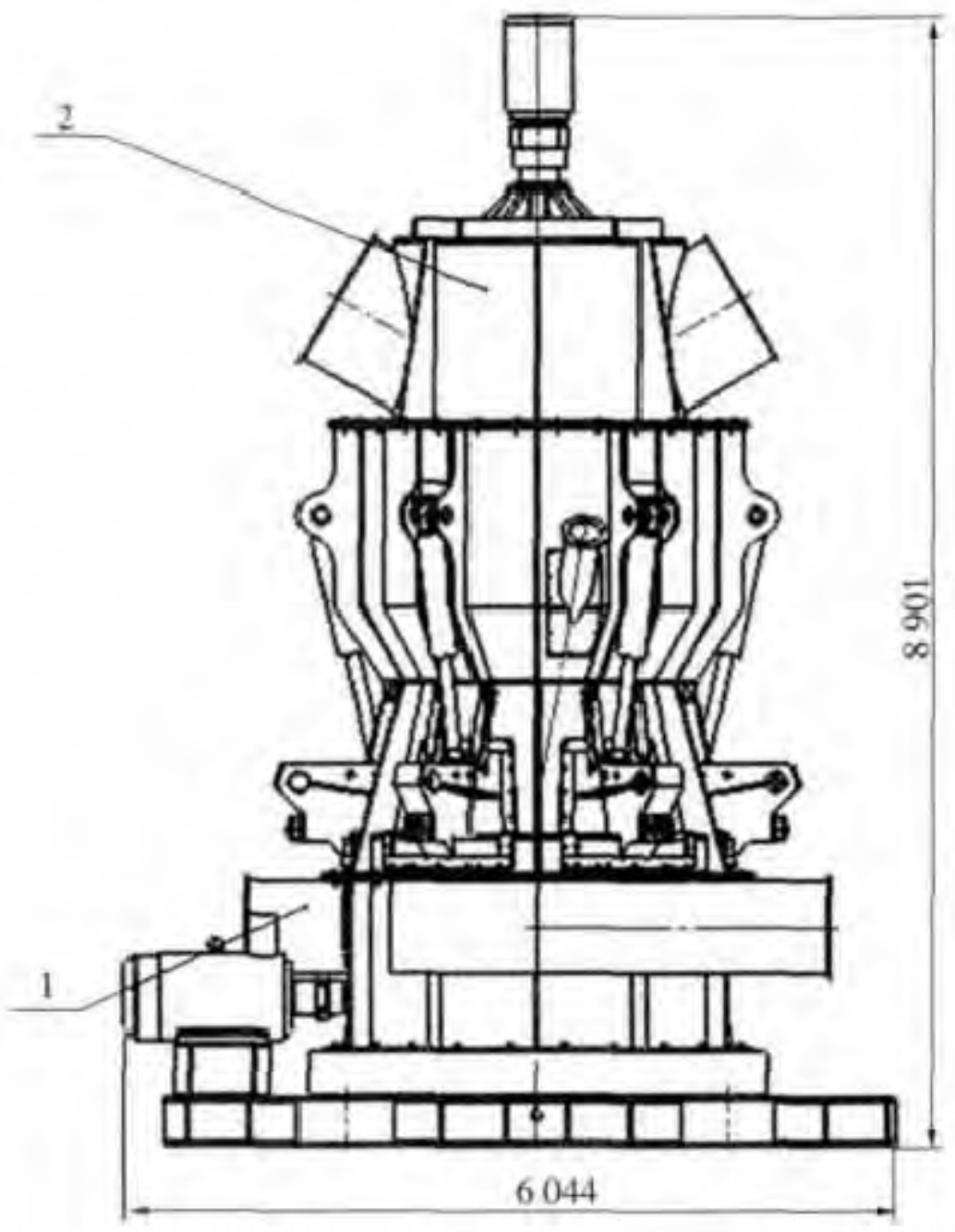

Fig. 3 Vertical milling machine model

Fly collectors

The device is designed to yield $30 \sim 35 \mathrm{t} / \mathrm{h}$, which has respectively two large cyclone collector and baghouse for collection, and gas delivery device by means delivery.Since the maximum transmission capacity of the gas delivery system is designed for $12 \mathrm{t} / \mathrm{h}$, it requires the collection efficiency cyclone collector is about $70 \%$ to $80 \%$, so we specially designed two large cyclone collector, whose efficiency is about $75 \%$, under production conditions which can collect particles larger than 5 equivalent diameter. $75 \mu \mathrm{m}$. Baghouse is as the last means to collect finished particles, whose efficiency is about $99.99 \%$, and which collect the finished product is approximately $10 \mathrm{t} / \mathrm{h}$. Reached 
dust efficiently work under conditions leave some margin, effectively improve equipment utilization, reduce investment and operating costs [10].

\section{process advantages}

The new vertical milling machine grinding fly ash technology has advantages in addition to the general mill, but also has the following characteristics:

(1)Improved Design of vertical milling machine makes it possible to effectively grinding fly it from the tube mill traditional mode of production improvement.

(2)Closed system designe makes the system further reduce costs and energy consumption in operation, and avoid the occurrence of open system appears baghouse ash particles into the atmosphere in case of damage in the harsh conditions of environmental pollution;

(3) small cyclone system design allows the system to ensure normal production under negative pressure inside the mill production, to avoid the seal is not good.

\section{Summary}

Vertical milling machine fly grinding process is a way to significantly reduce investment and operating costs, increase productivity, reduce floor space, new technology to reduce energy consumption and environmental pollution, save energy can be substantial. The process is a domestic initiative, the fly ash handling a new way, and has been successfully applied, with very good promotion of practical value.

\section{References}

[1] Chen Lei, Dai Juan, talk about the peak, and so on. Powder coal ash utilization and generalized coarse ash grinding mill Characteristics [J]. Mining machinery, 2004 (10): 13.

[2] Hao small non, Rao starter, Li Zhou. Situation and Prospect of Ash [J]. Mining Machinery, 2006,34 (10): 6-8.

[3] Huang Mei. On Ash Utilization [J]. Fujian Building Materials, 2013,14 (1): 20-23.

[4] Yang Bao, Zhu Chunqi. Fly low open circuit tube mill efficiency reasons and Improvement [J]. China Building Materials News, 2008 (3): 1-2.

[5] Talks about. HRM4800 vertical mill in 5000t / d cement clinker production line application [J]. China cement, 2009 (3): 51-55.

[6] Wu Jing. Development and application of grinding equipment [J]. Technology and the market, 2012,19 (11): 24 - 26.

[7] segment Mingnan, Zhang Yongjie. High slag fine powder vertical milling machine operating characteristics [J]. Steel Technology, 2014 (1): 23-30.

[8] Weixin Li, Zhang Hong, Wang calibration. Numerical Method cyclone flow field [J]. Zhengzhou University: Engineering Science, 2005,26 (1): 57-60.

[9] Qi navy. Numerical simulation and energy-saving vertical mill classifier classifying flow field [D]. Mianyang: Southwest University of Science and Mechanical Engineering, 2012.

[10] Ye Yuqi, money to pay level. Values are based on response surface methodology bag filter cleaning performance of research [J]. Environmental Science, 2012,32 (12): 3087--3094. 